\title{
Mitral valve anatomy: implications for transcatheter mitral valve interventions
}

Jose L. Zamorano ${ }^{*}$, MD, PhD; Ariana González-Gómez ${ }^{1}, \mathrm{MD}$; Patrizio Lancellotti² ${ }^{2}$ MD, PhD

1. University Hospital Ramón y Cajal, Madrid, Spain; 2. University Hospital of Liege, Liege, Belgium

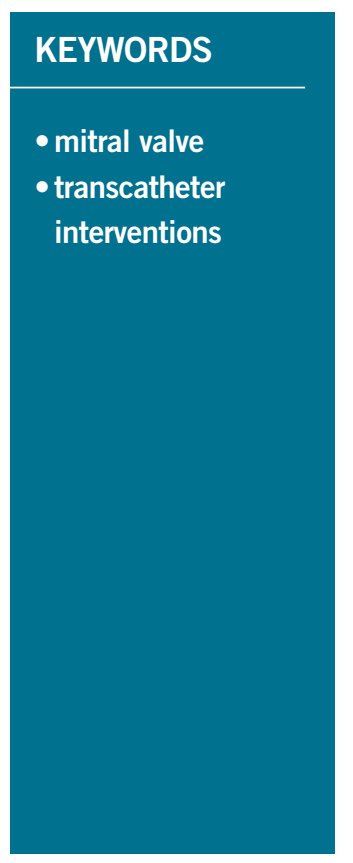

\section{Abstract}

Mitral regurgitation is a common valvular heart disease and its prevalence is expected to increase with population ageing. Percutaneous techniques for the treatment of mitral regurgitation are emerging as an alternative therapeutic option. However, the mitral valve is a complex structure, and a comprehensive understanding of the anatomy of the mitral valve apparatus and its surrounding structures is crucial for a correct selection of patients and the success of transcatheter mitral valve interventions.

\footnotetext{
*Corresponding author: University Hospital Ramón y Cajal, Carretera de Colmenar Km 9.400, 28034 Madrid, Spain. E-mail: zamorano@secardiologia.es
} 


\section{Introduction}

Mitral regurgitation (MR) is increasingly prevalent despite the reduced incidence of rheumatic disease, and its prevalence is expected to increase due to population ageing. Approximately $10 \%$ of people $\geq 75$ years have significant MR, and these patients have decreased survival ${ }^{1}$.

The mitral valve (MV) apparatus is a complex anatomical and functional structure ${ }^{2}$. Echocardiography in two and three dimensions is the clinical tool of choice for assessment of the MV. Two-dimensional (2D) echocardiography and especially threedimensional (3D) echocardiography have provided detailed morphologic and functional assessment, allowing a better understanding of the MV apparatus.

MR can be classified as organic or primary MR when the underlying disorder is intrinsic to one of the components of the MV, and functional or secondary when the MR is due to subvalvular or valvular deformations caused by left ventricular (LV) remodelling and dysfunction despite a structurally normal $\mathrm{MV}^{3}$.

In patients with severe chronic symptomatic MR or asymptomatic MR but recent onset of atrial fibrillation (AF), pulmonary hypertension or LV dysfunction, surgery is the treatment of choice, MV repair being preferable to replacement when feasible. The treatment of functional MR remains controversial ${ }^{4}$. However, one half of patients with severe MR are not referred for surgery, mainly due to advanced age, LV dysfunction or the presence of comorbidities ${ }^{5}$. The development of transcatheter MV interventions for the treatment of MR in recent years has grown as an alternative therapy for these patients. MV interventions, and particularly percutaneous MV repair techniques, are based on the same principles as MV surgery, and for each surgical technique there is a percutaneous equivalent ${ }^{6}$. Echocardiography remains the main imaging technique for MV anatomy assessment, but other non-invasive imaging techniques, such as multislice computed tomography, may also provide anatomical details facilitating patient selection and procedural guidance (e.g., identifying annular and leaflet calcifications, or the optimal transseptal or apical puncture site).

Since the MV is a complex structure, for the selection of patients and the performance of these procedures, a correct and detailed understanding of the anatomy of the MV apparatus and its surrounding structures is essential. The aim of this review is to describe the anatomy of the MV, focusing on its implications for transcatheter MV interventions.

\section{The mitral valve apparatus}

The MV apparatus is a complex anatomical and functional structure, comprising several components (MV annulus, mitral leaflets, subvalvular apparatus with tendinous cords and papillary muscles), which along with the left ventricle (LV) and atrium are essential for integrity and proper valve function ${ }^{2}$.

\section{MITRAL VALVE ANNULUS}

\section{A) ANATOMY}

The MV annulus represents the tissue that connects the left atrium (LA), LV and mitral leaflets. It is a dynamic, D-shaped orifice ${ }^{7}$. An area of fibrous continuity connects the anterior leaflet of the MV with the aortic valve, known as the aortic-mitral curtain. The ends of the area of fibrous continuity are two rigid structures, the right and left fibrous trigones. The right fibrous trigone is contiguous with the membranous septum and non-coronary cusps of the aortic valve, whereas the left fibrous trigone is contiguous with the left coronary cusp (Figure 1). The mitral annulus to aortic annulus angle changes dynamically over the cardiac cycle ${ }^{2,8,9}$. On the other hand, the posterior mitral annulus is more loosely anchored to its surrounding tissue. The absence of a fibrous structure as opposed to the aortic-mitral curtain explains why annular dilatation and calcification occur most frequently in the posterior segment of the annulus, with an increase in the septal-lateral diameter, potentially leading to inadequate leaflet coaptation and MR. The MV annulus has a 3D saddle-shaped appearance, with elevated anterior and posterior segments (the highest point corresponding to the anterior segment), and lower points represented by the trigones ${ }^{10}$.

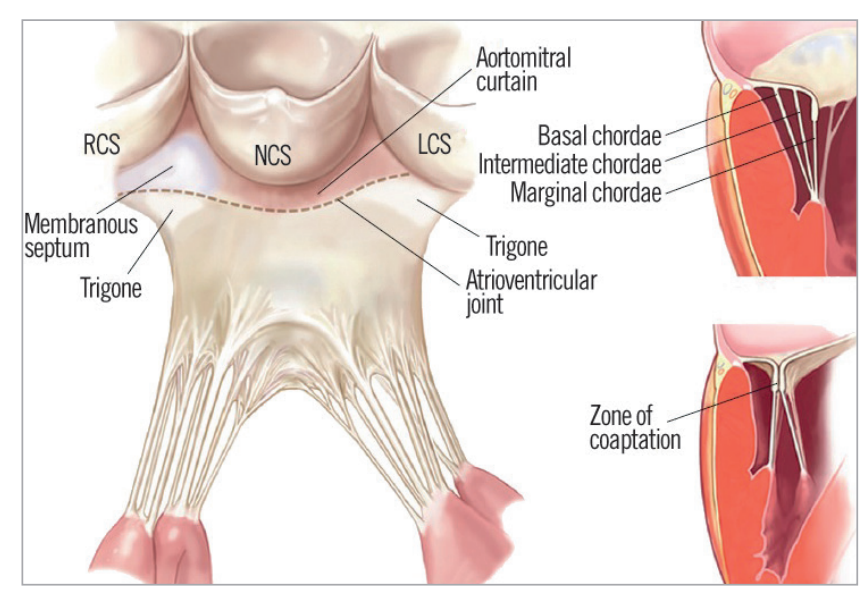

Figure 1. Drawing of the mitral subvalvular apparatus. LCS: left coronary sinus; NCS: non-coronary sinus; RCS: right coronary sinus. (Reproduced with permission)

Another relevant anatomical feature which must be considered before the performance of a percutaneous procedure involving the MV annulus is the coronary sinus. The coronary sinus encircles the posterior MV annulus. The great cardiac vein originates at the anterior interventricular groove, turning at the atrioventricular junction, fusing with the oblique vein of the LA to become the coronary sinus. During transcatheter procedures, consideration must be given to the fact that interindividual variability of the venous system is high, and that the coronary sinus Thebesian valve has significant morphological variability which can make the procedure more complex ${ }^{11}$. Variability of the distance between the coronary sinus and the MV is substantial, being even greater in cases of significant MR due to dilatation of the annulus, when the sinus is lifted away from the posterior segment. Attention should also be paid to the circumflex coronary artery which is usually in close proximity to the coronary sinus ${ }^{12,13}$. 


\section{B) ANNULOPLASTY PROCEDURES}

In order to achieve effective and durable results after surgery, annuloplasty is a key step ${ }^{14}$. Several percutaneous techniques have been developed in an attempt to remodel the mitral annulus. Transcatheter annuloplasty can be performed indirectly via the coronary sinus or by approaching the annulus directly via the LA or LV.

Indirect annuloplasty techniques insert a shortening device into the coronary sinus, indirectly affecting the posterior mitral annulus geometry due to its close relation with the coronary sinus, in an attempt to imitate the effect of a ring in a surgical annuloplasty. Several devices such as the CARILLON ${ }^{\circledR}$ Mitral Contour System ${ }^{\circledR 15}$ (Cardiac Dimensions Inc., Kirkland, WA, USA), MONARC ${ }^{16}$ (Edwards Lifesciences, Irvine, CA, USA), and Viacor PTMA Device $^{17}$ (Viacor, Wilmington, MA, USA) have been used.

Several anatomical features should be taken into consideration for the success of these devices, such as the presence and morphology of the coronary sinus and its relationship with the surrounding structures, as well as the anatomy of the circumflex coronary artery. Limitations arise from the aforementioned substantial interindividual variability between the coronary sinus and the mitral annulus itself, which may reduce efficacy. Extrinsic coronary artery compression has also been reported ${ }^{13,18}$, and device fracture due to mechanical stress of the coronary sinus has often been reported.

Direct annuloplasty techniques using devices such as the Mitralign system (Mitralign, Inc., Tewksbury, MA, USA), the GDS Accucinch $^{\circledR}$ System (Guided Delivery Systems, Santa Clara, CA, USA) and the Cardioband Annuloplasty System (Valtech Cardio, Or Yehuda, Israel) use a direct access to the mitral annulus, in an attempt to reproduce surgical annuloplasty more closely and avoid the potential limitations of indirect annuloplasty. However, they are technically more complicated than indirect annuloplasty, and annular calcification and the potential for leaflet damage and circumflex artery damage are of concern ${ }^{19}$. Other techniques such as energymediated annuloplasty have also been attempted.

\section{MITRAL VALVE LEAFLETS}

\section{A) ANATOMY}

The MV is formed by two leaflets, the anterior or aortic leaflet and the posterior or mural leaflet. The anterior leaflet has a trapezoid shape and is anchored to the fibrous portion of the mitral valve, in continuity with the aortic cusps. It is larger, thicker and longer than the posterior leaflet, with a wider surface and a shorter base, occupying one third of the annulus circumference. In order to facilitate diagnosis and communication, the valve is virtually divided into lateral (A1), central (A2) and medial (A3) scallops. The posterior or mural leaflet occupies two thirds of the annulus circumference, but is shallower. It has two clefts in its free border, dividing it into lateral (P1), central (P2) and medial (P3) scallops. Additional leaflet tissue, commissural or junctional, is found at the anterolateral (A1-P1) or posteromedial (A3-P3) commissures. The free borders of the leaflets are anchored to the subvalvular apparatus via the tendinous cords ${ }^{20,21}$.

The atrial surface of the leaflets is smooth. A rough zone starts approximately $1 \mathrm{~cm}$ from the distal leaflet edge. When the leaflets coapt, the irregular soft surface of this zone helps maintain the seal ${ }^{7}$. In systole the leaflets coapt over a height of $8 \mathrm{~mm}$ on average, providing a coaptation reserve in cases of annular dilatation ${ }^{22}$.

\section{B) LEAFLET PROCEDURES}

The main goal of leaflet procedures is to improve leaflet coaptation and reduce the regurgitant orifice. Currently, the most advanced and used percutaneous technology for MV repair is the MitraClip system (Abbott Vascular, Abbott Park, IL, USA). This catheter-based technique is similar to the Alfieri technique, since it implants a clip that holds the free edges of the mid portions of the anterior and posterior mitral leaflets together, reducing the degree of $\mathrm{MR}^{23}$. The MitraClip procedure has been shown to be a feasible and safe alternative for patients ineligible for surgery ${ }^{24}$.

Patient selection should be based on the presence of moderate to severe or severe MR, mechanism, aetiology of MR (degenerative or functional MR), and several anatomical premises. Therefore, for the success of the procedure, anatomical considerations concerning the MV have to be taken into account both for selection of patients and during the procedure itself, where echocardiography, in two and three dimensions, plays an essential role in understanding the valve anatomy.

Anatomical criteria determined by transoesophageal echocardiography (TEE) were defined in the EVEREST trial ${ }^{25}$. First of all, central jets are the ones which show the best results since the MitraClip system creates a double orifice at the level of A2-P2. The degree of thickness and calcification of mitral leaflets should also be assessed, since the presence of significant calcification especially in the grasping area makes the patient unsuitable for the procedure. A coaptation length of at least $2 \mathrm{~mm}$ and a depth below the mitral annular plane of no more than $11 \mathrm{~mm}$ must be available. In cases of flail leaflets, the gap and the width of the flail segment should be no more than 10 and $15 \mathrm{~mm}$, respectively (Figure 2). European experience has shown that the MitraClip device can be successfully implanted in patients with a more complex MV anatomy. The MV area must be more than $4 \mathrm{~cm}^{2}$ in order to avoid mitral stenosis. Another important issue to assess is the dimension of the LA and interatrial septal morphology, with the presence of patent foramen

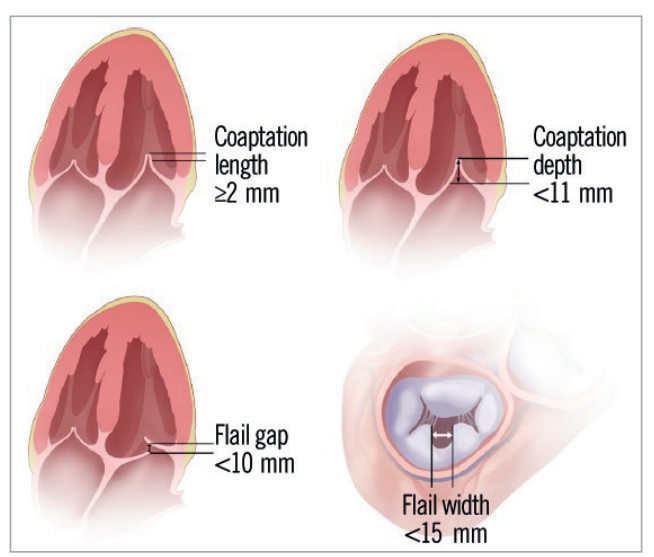

Figure 2. Key anatomical eligibility criteria for MitraClip implant. (Reproduced with permission from Abbott) 
ovale depicted. The accepted anatomic measurements and characteristics for MitraClip patient selection are summarised in Table 1.

Table 1. Anatomical criteria for selection of patients for MitraClip implantation.

\begin{tabular}{|l|l|l|}
\hline Aetiology & \multicolumn{1}{|c|}{ Suitable for MC } & \multicolumn{1}{c|}{ Unsuitable for MC } \\
\hline MV area & $>4 \mathrm{~cm}^{2}$ & $\begin{array}{l}\text { Degenerative or functionaled mitral leaflets or clefts, } \\
\text { lack of primary and secondary chordal } \\
\text { support, rheumatic or endocarditic }\end{array}$ \\
\hline MR jet & Central & Significant mitral stenosis \\
\hline Calcification & None (grasping area) & Eccentric and multiple jets \\
\hline $\begin{array}{l}\text { Specific } \\
\text { measurements }\end{array}$ & $\begin{array}{l}\text { Flail width }<15 \mathrm{~mm} \\
\text { Flail gap }<10 \mathrm{~mm} \\
\text { Coaptation depth }<11 \mathrm{~mm} \\
\text { Coaptation length }>2 \mathrm{~mm}\end{array}$ & Gap between leaflets $>2 \mathrm{~mm}$ \\
\hline
\end{tabular}

MC: MitraClip; MR: mitral regurgitation; MV: mitral valve

During the procedure, understanding and consideration of anatomy is important for success. In the first step of the procedure, the location of the transseptal puncture is crucial, since it must be performed in a posterior and superior location and at a certain distance from the valvular plane that enables manipulation of the system within the left atrium and grasping of leaflets. To ensure a correct location, 2D TEE imaging planes, using a short-axis view at the base for anterior-posterior orientation $\left(30-45^{\circ}\right)$, a bicaval view for superior-inferior orientation $\left(90-120^{\circ}\right)$ and a four-chamber view to identify the height above the MV, have to be used. Three-dimensional echocardiography (3DE), obtaining the whole interatrial septum in one view, avoids shifting from one plane to another. Once inside the LA, the MitraClip system should be placed above the MV in its mid portion, and perpendicular to the line of coaptation, directed towards the largest proximal isovelocity surface area (PISA). A 3DE en face view of the MV from the LA perspective allows visualisation in one image of the whole MV for correct orientation (Figure 3). Once in the $L V$, repositioning may be needed. During grasping of leaflets, 2D TEE imaging is needed, helping 3DE confirm correct bridging between the valves and the clip. Before release, MV gradient and orifice area must be evaluated to avoid significant mitral stenosis. In cases of unsatisfactory MR reduction, repositioning of the clip or the implant of a second clip may be considered ${ }^{26}$.

\section{TENDINOUS CORDS AND PAPILLARY MUSCLES}

The tendinous cords are fibrous strings that originate from the papillary muscle tips and insert into the ventricular aspects of the leaflets ${ }^{27}$. There is a wide variability in chordal anatomy and branching patterns, but cords are classified according to their point of leaflet insertion into marginal, intermediate, and basal cords. Marginal cords are thinner, insert into the leaflet tips, and have limited extensibility, to avoid leaflet prolapse. Basal cords are thicker and have a tighter collagen structure, which makes them more extensible ${ }^{28}$. The basal cords are only found in the posterior leaflet, connecting the ventricular surface of the posterior leaflet to the papillary muscles (Figure 1).

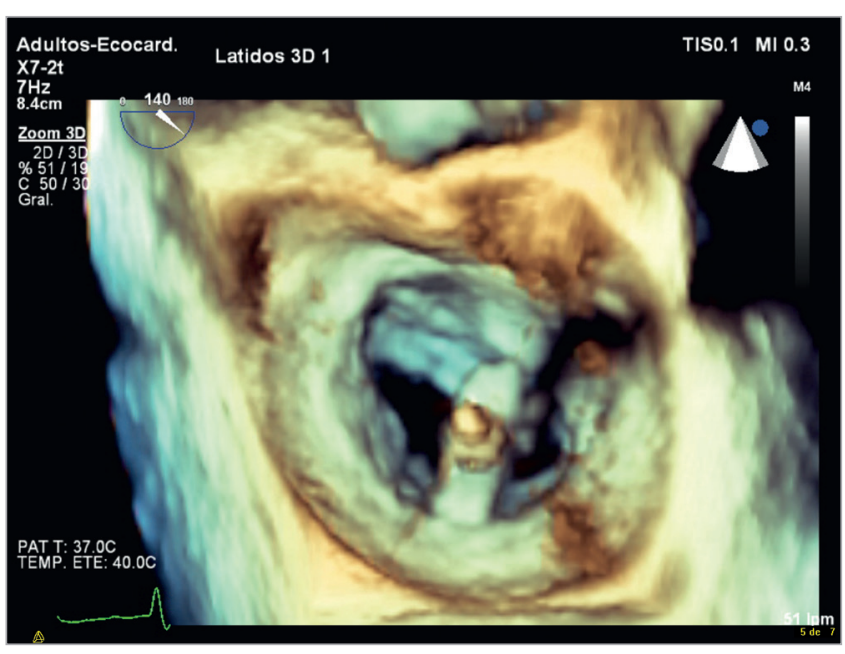

Figure 3. A 3DE en face view of the mitral valve from the left atrium perspective allows visualisation in one image of the whole mitral valve for correct orientation of the MitraClip device.

The papillary muscles are labelled according to their relationship with mitral commissures as anterolateral and posteromedial papillary muscles. They originate from the apical third of the LV and protrude into the cavity. The anterolateral papillary muscle has a single head and dual blood supply from the circumflex and anterior descending coronary arteries. On the other hand, the posteromedial papillary muscle is smaller, most commonly has two heads and is usually supplied by a single branch of the circumflex or right coronary artery, which makes it particularly susceptible to ischaemia and the development of ischaemic $\mathrm{MR}^{2,7}$.

The papillary muscle and cord system work together in maintaining an effective systolic coaptation seal. Fibroelastic degeneration can induce tissue retraction, making the cords vulnerable to rupture, whereas cords inappropriately long in cases of myxomatous degeneration can induce mitral prolapse ${ }^{29}$.

As already discussed, the MitraClip system is a transcatheter approach targeting degenerative and functional MR. With the intention of connecting the myocardium and the mitral leaflets, artificial tendinous cords have also been implanted via transseptal or transapical approaches ${ }^{30,31}$.

\section{THE LEFT VENTRICLE}

The MV is directly connected to the LV via the papillary muscles, and therefore changes in the ventricular geometry directly affect MV functioning. LV remodelling due to ischaemia, or LV dilatation can induce MV tethering due to papillary muscle displacement and consequently lack of coaptation and $\mathrm{MR}^{32,33}$.

Catheter techniques such as the percutaneous iCoapsys technique based on the Coapsys surgical system (Edwards Lifesciences) have been developed. It is a technique which remodels the LV, implanting two epicardial pads on both sides of the LV, introducing a transventricular bridge between them through the pericardial space. Indirectly, the device potentially reduces the septal-lateral distance, and the papillary muscles are drawn closer to the leaflets, reducing $\mathrm{MR}^{34}$. 


\section{Percutaneous treatment of MV replacement}

Transcatheter aortic valve replacement is already an established technique for the treatment of patients with severe aortic stenosis and at high surgical risk; however, the development of transcatheter MV replacement has not run parallel. This is mainly due to the complexity of the MV anatomy, which makes implantation of a percutaneous valve in the mitral position much more challenging than in an aortic position. Anchoring is one of the main problems due to the asymmetry of the MV annulus, the absence of a single valvular plane, and the constant movement of the mitral annulus. The radial force could potentially be non-effective and cause complications. LV outflow tract obstruction and aortic valve deformation are other issues that may lead to complications. The tendinous cords may impede positioning, expansion and anchoring. Furthermore, paravalvular leaks may not be as well tolerated in the mitral position as in the aortic position with the development of high gradients.

Currently, despite the potential difficulties, several transcatheter MV replacement technologies, transapical or transseptal, are in various stages of evaluation and development, and are showing promising results ${ }^{35-37}$.

\section{Conclusions}

With the emergence and development of transcatheter techniques for the treatment of MR, special attention has been focused on the MV anatomy. The MV is a complex anatomical and functional structure, and a comprehensive understanding of the anatomy of the MV apparatus and its surrounding structures is crucial for a correct selection of patients, procedural success and further development of these transcatheter technologies.

\section{Conflict of interest statement}

The authors have no conflicts of interest to declare.

\section{References}

1. Nkomo VT, Gardin JM, Skelton TN, Gottdiener JS, Scott CG, Enriquez-Sarano M. Burden of valvular heart disease: a populationbased study. Lancet. 2006;368:1005-11.

2. Castillo JG, Solís J, González-Pinto A, Adams DH. Surgical echocardiography of the mitral valve. Rev Esp Cardiol (Engl Ed). 2011;64:1169-81

3. Enriquez-Sarano M, Akins CW, Vahanian A. Mitral regurgitation. Lancet. 2009;373:1382-94.

4. Vahanian A, Alfieri O, Andreotti F, Antunes MJ, BarónEsquivias G, Baumgartner H, Borger MA, Carrel TP, De Bonis M, Evangelista A, Falk V, Lung B, Lancellotti P, Pierard L, Price S, Schäfers HJ, Schuler G, Stepinska J, Swedberg K, Takkenberg J, Von Oppell UO, Windecker S, Zamorano JL, Zembala M; ESC Committee for Practice Guidelines (CPG); Joint Task Force on the Management of Valvular Heart Disease of the European Society of Cardiology (ESC); European Association for Cardio-Thoracic Surgery (EACTS). Guidelines on the management of valvular heart disease (version 2012): the Joint Task Force on the Management of Valvular Heart Disease of the European Society of Cardiology
(ESC) and the European Association for Cardio-Thoracic Surgery (EACTS). Eur J Cardiothorac Surg. 2012;42:S1-44.

5. Mirable M, Lung B, Baron G, Messika-Zeitoun D, Détaint D, Vanoverschelde JL, Butchart EG, Ravaud P, Vahanian A. What are the characteristics of patients with severe, symptomatic, mitral regurgitation who are denied surgery? Eur Heart J. 2007;28:1358-65.

6. Nombela-Franco L, Urena M, Ribeiro HB, Rodés-Cabau J. Advances in percutaneous treatment of mitral regurgitation. Rev Esp Cardiol (Engl Ed). 2013;66:566-82.

7. Dal-Bianco JP, Levine RA. Anatomy of the mitral valve apparatus: role of 2D and 3D echocardiography. Cardiol Clin. 2013;31:151-64.

8. Mureisan H. The clinical anatomy of the mitral valve. Clin Anat. 2009;22:85-98.

9. Timek TA, Green GR, Tibayan FA, Lai DT, Rodriguez F, Liang D, Daughters GT, Ingels NB Jr, Miller DC. Aorto-mitral annular dynamics. Ann Thorac Surg. 2003;76:1944-50.

10. Anwar AM, Soliman OI, ten Cate FJ, Nemes A, McGhie JS, Krenning BJ, van Geuns RJ, Galema TW, Geleijnse ML. True mitral annulus diameter is underestimated by two-dimensional echocardiography as evidenced by real time three-dimensional echocardiography and magnetic resonance imaging. Int $J$ Cardiovasc Imaging. 2007;23:541-7.

11. Van de Veire NR, Marsan NA, Schuijf JD, Bleeker GB, Wijffels MC, van Erven L, Holman ER, De Sutter J, van der Wall EE, Schalij MJ, Bax JJ. Noninvasive imaging of cardiac venous anatomy with 64-slice-computed tomography and noninvasive assessment of LV dyssynchrony by 3-dimensional tissue synchronization imaging in patients with heart failure scheduled for cardiac resynchronization therapy. Am J Cardiol. 2008;101:1023-9.

12. Masselli D, Guarracino F, Chiaramonti F, Mangia F, Borelli G, Minzioni G. Percutaneous mitral annuloplasty: an anatomic study of human coronary sinus and its relation with mitral valve annulus and coronary arteries. Circulation. 2006;114:377-80.

13. Choure AJ, Garcia MJ, Hesse B, Sevensma M, Maly G, Greenberg NL, Borzi L, Ellis S, Tuzcu EM, Kapadia SR. In vivo analysis of the anatomical relationship of coronary sinus to mitral annulus and left circumflex coronary artery using cardiac multidetector computed tomography: implications for percutaneous coronary sinus mitral annuloplsaty. J Am Coll Cardiol. 2006;48:1938-45.

14. Gillinov AM, Cosgrove DM, Blackstone EH. Durability of mitral valve repair for degenerative disease. $J$ Thorac Cardiovasc Surg. 1998;116:734-43.

15. Schofer J, Siminiak T, Haude M, Herrman JP, Vainer J, Wu JC, Levy WC, Mauri L, Feldman T, Kwong RY, Kaye DM, Duffy SJ, Tübler T, Degen H, Brandt MC, Van Bibber R, Goldberg S, Reuter DG, Hoppe UC. Percutaneous mitral annuloplasty for functional mitral regurgitation: results of the CARILLON Mitral Annuloplasty Device European Union Study. Circulation. 2009;120:326-33.

16. Harnek J, Webb JG, Kuck KH, Tschope C, Vahanian A, Buller CE, James SK, Tiefenbacher CP, Stone GW. Transcatheter implantation of the MONARC coronary sinus device for mitral regurgitation: 1-year results from the EVOLUTION phase I study 
(Clinical Evaluation of the Edwards Lifesciences Percutaneous Mitral Annuloplasty System for the Treatment of Mitral Regurgitation). JACC Cardiovasc Interv. 2011;4:115-22.

17. Sack S, Kahlert P, Bilodeau L, Pièrard LA, Lancellotti P, Legrand V, Bartunek J, Vanderheyden M, Hoffmann R, Schauerte P, Shiota T, Marks DS, Erbel R, Ellis SG. Percutaneous transvenous mitral annuloplasty: initial human experience with a novel coronary sinus implant device. Circ Cardiovasc Interv. 2009;2:277-84.

18. Tops LF, Van de Veire NR, Schuijf JD, de Roos A, van der Wall EE, Schalij MJ, Bax JJ. Noninvasive evaluation of coronary sinus anatomy and its relation to the mitral valve annulus: implications for percutaneous mitral annuloplasty. Circulation. 2007;115:1426-32.

19. Feldman T, Cilingiroglu M. Percutaneous leaflet repair and annuloplasty for mitral regurgitation. J Am Coll Cardiol. 2011;57: 529-37.

20. Ho SY. Anatomy of the mitral valve. Heart. 2002;88 Suppl 4:iv5-10.

21. Okamoto H, Itoh Y, Nara Y. Geometric analysis of the anterior leaflet and mitral valve orifice in cadaveric hearts. Circ J. 2007;71:1794-9.

22. Van Mieghem NM, Piazza N, Anderson RH, Tzikas A, Nieman K, De Laat LE, McGhie JS, Geleijnse ML, Feldman T, Serruys PW, de Jaegere PP. Anatomy of the mitral valvular complex and its implications for transcatheter interventions for mitral regurgitation. J Am Coll Cardiol. 2010;56:617-26.

23. Feldman T, Wasserman HS, Herrmann HC, Gray W, Block PC, Whitlow P, St Goar F, Rodriguez L, Silvestry F, Schwartz A, Sanborn TA, Condado JA, Foster E. Percutaneous mitral valve repair using the edge-to-edge technique. Six-month results of the EVEREST Phase I Clinical Trial. J Am Coll Cardiol. 2005;46:2134-40.

24. Mauri L, Foster E, Glower DD, Apruzzese P, Massaro JM, Herrmann HC, Hermiller J, Gray W, Wang A, Pedersen WR, Bajwa T, Lasala J, Low R, Grayburn P, Feldman T; EVEREST II Investigators. Four-year results of a randomized controlled trial of percutaneous repair versus surgery for mitral regurgitation. $J \mathrm{Am}$ Coll Cardiol. 2013;23:317-28.

25. Feldman T, Kar S, Rinaldi M, Fail P, Hermiller J, Smalling R, Whitlow PL, Gray W, Low R, Herrmann HC, Lim S, Foster E, Glower D; EVEREST Investigators. Percutaneous mitral valve repair with the MitraClip system: safety and midterm durability in the initial EVEREST cohort. J Am Coll Cardiol. 2009;54:686-94.

26. Wunderlich NC, Beigel R, Siegel RJ. The role of echocardiography during mitral valve percutaneous interventions. Cardiol Clin. 2013;31:237-70.
27. Millington-Sanders C, Meir A, Lawrence L, Stolinski C. Structure of chordae tendineae in the left ventricle of the human heart. J Anat. 1998;192:573-81.

28. Liao J, Vesely I. A structural basis for the size-related mechanical properties of mitral valve chordae tendineae. $J$ Biomech. 2003;36:1125-33.

29. Anyanwu AC, Adams DH. Etiologic classification of degenerative mitral valve disease: Barlow's disease and fibroelastic deficiency. Semin Thorac Cardiovasc Surg. 2007;19:90-6.

30. Chandra S, Salgo IS, Sugeng L, Weinert L, Tsang W, Takeuchi M, Spencer KT, O'Connor A, Cardinale M, Settlemier S, Mor-Avi V, Lang RM. Characterization of degenerative mitral valve disease using morphologic analysis of real-time three-dimensional echocardiographic images: objective insight into complexity and planning of mitral valve repair. Circ Cardiovasc Imaging. 2011;4:24-32.

31. Pepi M, Tamborini G, Maltagliati A, Galli CA, Sisillo E, Salvi L, Naliato M, Porqueddu M, Parolari A, Zanobini M, Alamanni F. Head-to-head comparison of two- and three-dimensional transthoracic and transesophageal echocardiography in the localization of mitral valve prolapse. J Am Coll Cardiol. 2006;48: 2524-30.

32. Hueb AC, Jatene FB, Moreira LF, Pomerantzeff PM, Kallás E, de Oliveira SA. Ventricular remodeling and mitral valve modifications in dilated cardiomyopathy: new insights from anatomic study. J Thorac Cardiovasc Surg. 2002;124:1216-24.

33. Otto CM. Clinical practice. Evaluation and management of chronic mitral regurgitation. N Engl J Med. 2001;345:740-6.

34. Pedersen WR, Block P, Leon M, Kramer P, Kapadia S, Babaliaros V, Kodali S, Tuzcu EM, Feldman T. iCoapsys mitral valve repair system: percutaneous implantation in an animal model. Catheter Cardiovasc Interv. 2008;72:125-31.

35. Lutter G, Pokorny S, Frank D, Cremer J, Lozonschi L. Transapical mitral valve implantation: the Lutter valve. Heart Lung Vessel. 2013;5:201-6.

36. Banai S, Jolicoeur EM, Schwartz M, Garceau P, Biner S, Tanguay JF, Cartier R, Verheye S, White CJ, Edelman E. Tiara: a novel catheter-based mitral valve bioprosthesis: initial experiments and short-term pre-clinical results. $\mathrm{J} \mathrm{Am}$ Coll Cardiol. 2012;60:1430-1.

37. Banai S, Verheye S, Cheung A, Schwartz M, Marko A, Lane R, Jolicoeur EM, Garceau P, Biner S, Tanguay JF, Edelman ER, White CJ. Transapical mitral implantation of the Tiara bioprosthesis: pre-clinical results. JACC Cardiovasc Interv. 2014;7:154-62. 